\title{
Autogenic inhibition versus reciprocal inhibition techniques on spastic children
}

\author{
Mohamed Serag Eldein Mostafa ${ }^{1}$ and Mohamed Ali Elshafey ${ }^{2}$ \\ ${ }^{1}$ Associate professor Department of Basic Sciences, Faculty of Physical Therapy, Cairo University, Egypt \\ ${ }^{2}$ Associate professor Department of physical Therapy for Growth and Developmental Disorders in Children and it is Surgery - Faculty of Physical Therapy, Cairo University, Egypt
}

\begin{abstract}
Background: Studying the result of autogenic inhibition versus reciprocal inhibition techniques on the children spasticity is a strategy for determining which of them is the most actual in reducing spasticity.
\end{abstract}

Objective: To investigate the efficacy of autogenic inhibition versus reciprocal inhibition on hemiplegic children spasticity.

Design: Pretest-Posttest trial.

Setting: Laboratories of comprehensive rehabilitation center.

Subjects: Forty spastic hemiplegic children of both genders ranged in age from seven to nine years contributed in this study, they were being randomly selected from comprehensive rehabilitation center and assigned into two groups of equal number (each group 20 child).

Intervention: Group (A) underwent autogenic inhibition technique while group (B) underwent reciprocal inhibition technique.

Measurements: H\M ratio and Muscle Functional Magnetic Resonance Imaging used to assess muscle spasticity for both groups before and after the intervention.

Results: There were significant reduction in H\M ratio for both groups after intervention immediately in favor of group A and significant improvements in Muscle Functional Magnetic Resonance Imaging for group A while non-significant for group B.

Conclusions: Autogenic inhibition more effective than reciprocal inhibition technique on decreasing hemiplegic children spasticity.

\section{Introduction}

Autogenic inhibition reflex is a sudden relaxation of muscle upon the development of high tension. It is a self-induced, inhibitory, negative feedback prolong lengthen reaction against tear muscles. Golgi tendon organs are receptors responsible for that [1].

Autogenic inhibition (historically known as the inverse myotatic reflex or autogenetic inhibition) shows a decrease in the excitability of a contracting or stretched muscle that in the past has been merely ascribed to the increased inhibitory input arising from Golgi tendon organs (GTOs) within the same muscle. The reduced efferent (motor) send to the muscle through autogenic inhibition is a factor that will help muscle elongation [1].

Reciprocal inhibition process recognized as when the muscle spindle, which is placed within the muscle, tummy and stretches alongside with the muscle itself. When this occurs, the muscle spindle is activated and causes a reflexive contraction in the agonist's muscle (known as the stretch reflex) and relaxation in the antagonist muscle [1,2].

Reciprocal inhibition mediated via the muscle spindle Ia afferents from the antagonist's muscle was identified and investigated in healthy subjects [3-5]. The reciprocal Ia inhibition is enhanced throughout voluntary activation of the antagonist, e.g. it prevents stretch reflexes in the antagonist's muscle as the muscle is passively stretched. In spastic patients, in hemiplegia in addition to paraplegia, the quantity of Ia reciprocal inhibition is reduced [5] and its regulation during (the remaining) voluntary movement is more or less eliminated [6].

While a significant decrease of reciprocal inhibition is seen in spastic patients, it has been difficult to correlate the amount of decrease with the clinical severity of spasticity. Nevertheless, some long-term studies may indicate a positive relationship. One group of researchers reported that the Ia inhibition returns with clinical recovery [7]. Another longitudinal study of stroke patient found that the development of Autogenetic Ib inhibition, or "non-reciprocal group I inhibition," has been identified in humans $[8,9]$. Through willing contraction of the muscle group, the inhibition seems to be reduced [10]. In animal experiments, this has been proven that during locomotion, there is not just a reduction of the di-/trisynaptic inhibition but also even the appearance of a "new" locomotor-related Ib excitation [11]. This could not be confirmed "reflex reversal" in experiments on human locomotion. The reports on changes in Ib inhibition during spasticity are conflicting. Delwaide and

${ }^{*}$ Correspondence to: Mohamed Serag, Physical Therapy department of Basic Sciences, Faculty of Physical Therapy, Cairo University, Egypt, E-mail: drsergany_79@hotmail.com

Key words: autogenic inhibition, reciprocal inhibition, spasticity, $h \backslash m$ ratio, muscle functional, magnetic resonance imaging

Received: August 20, 2018; Accepted: September 15, 2018; Published: September 19, 2018 
Pennisi $[12,13]$ stated that the Ib inhibition is reduced (and can even be reversed into facilitation), and the decline is associated with the degree of spasticity. Furthermore, they [13] describe that tizanidine reduces both spasticity and enhances the Ib inhibition.

Downes and others [14] could not approve a decrease in $\mathrm{Ib}$ inhibition in spasticity and show that the evident differences may depend on pathophysiological differences in cerebral and spinal spasticity. To summarize, the Ib inhibition has not been investigated as extensively in relation to spasticity as has reciprocal inhibition and presynaptic inhibition, and the results are conflicting. It is clear that further investigations, both on the normal function in motor control and the role in regulating muscle tone following supraspinal and spinal lesions, were warranted.

Hemiplegia accounts for approximately $30-40 \%$ of all people who are born with cerebral palsy $[15,16]$. Hemiplegic children had problems in proceeding fine motor hand activities and had abnormal upper limb posturing during walk and in any activities needed effort [17].

Using muscle functional Magnetic Resonance Imaging (mfMRI) in healthy and non-healthy people is an innovative, post-exercise, evaluation method to assess the quantity of metabolic muscle activity by quantifying shifts in T2-relaxation times of muscle water upon exercise $[18,19]$. Few studies are available investigating the muscle performance during activities these studies are solely based on EMG measurements therefore Magnetic resonance imaging (MRI) has the potential to provide a more reliable and objective assessment of muscle function than surface EMG [20]. Muscle functional MRI is an innovative technique that enables investigation of the activity pattern of muscles. The method relies on an acute activity-induced increase in transverse relaxation time (T2) of muscle water [21-23]. This increase in T2 causes an enhancement in signal intensity of activated muscles [24]. Despite its widespread use for evaluation of skeletal muscle and soft tissue elsewhere in the body.

There is a lack in the literature concerning the effect of autogenetic inhibition versus reciprocal inhibition on children spasticity. We hypothesize that there was no significant difference on children spasticity between autogenetic inhibition and reciprocal inhibition techniques.

\section{Subjects, materials and methods}

\section{Study design}

The design of the study was pre-test post-test design. The procedures followed agreed with the Institutional Ethical Committee Clearance (PACTR201801002940240), and written informed consent was taken from their legal guardians of the children.

\section{Subjects}

This study was conducted in the laboratories of comprehensive rehabilitation center. Forty spastic hemiplegic $\mathrm{CP}$ children of both sexes (22 B -18G) were assigned randomly into two equal groups of equal number (each group 20 child) randomly selected from comprehensive rehabilitation center according to the following criteria: Their ages were ranged from 7 to 9 years. They had grade 1 or $1+$ according to modified ashworth scale and grade II or III according to Manual Ability Classification Scale (MACS), they can understand and follow verbal commands and instructions included in the test. Children's in Group (A) consisted of 20 children (11 B and 9G) were received autogenetic inhibition technique, Children's in Group (B) consisted of 20 children $(9 \mathrm{~B}$ and $11 \mathrm{G})$ were received reciprocal inhibition technique.

\section{Instrumentation}

Hanson professional scale was used to measure weight and height [25]. Electromyography apparatus (A TeleMyo 2400 G2 Telemetry System, made in the USA) to measure $\mathrm{H} \backslash \mathrm{M}$ ratio and MRI was performed on a 3-T magnet (Siemens Magnetom Trio a Tim System with Syngo MR B13. Erlangen Germany).

\section{Procedure}

a) Assessment procedures: The assessors were blinded folded to group allocation.

I- weight and height assessment: The weight and height of both groups were measured by the Hanson professional scale before the intervention.

II- EMG Studies: $\mathrm{H} \backslash \mathrm{M}$ ratio for Bicepsbrachii from the upper limb was evaluated by EMG before, immediately after intervention and after $2 \mathrm{~min}$ post intervention on the spastic side of each children. The technical steps of the electro diagnostic test application EMG including; electrode placement, skin temperature correction, determination of nerve stimulation intensity and analysis of the evoked neuro- electrical response. The system comprises an electronic monitor and a report generation system. The archive stores all electrophysiological data including raw waveforms and limited demographic information (age, height, weight and gender). Official clinical staffs that undergo training by the manufacture typically perform the EMG tests. Each study is coded with the primary clinical indication for the (Biceps brachii muscle). For Hoffmann reflex of Biceps brachii muscle. Prior to electrode placement, the skin on the right upper arm was lightly rubbed with and cleaned with scrubbing alcohol to reduce signal impedance at the skin surface. The motor point was then specified for electrode placement. The motor point is defined as a muscle region in which the lowest possible incentive will produce minimum muscle contraction. The motor point of the biceps brachii (BB) was located approximately midway between the glenohumeral joint and the cubital crease. The cathode portion of the stimulating probe was placed in the predictable motor point region. With the train rate on the stimulator set at $10 \mathrm{pps}$, and the stimulus duration set at $1 \mathrm{msec}$ [26], the cathode was moved around belly of the muscle to find the motor point. Prior to placing the recording (G2) and reference $(\mathrm{Gl})$ electrodes, skin impedance was measured (Grass EZM Electrode Impedance Meter, Astro-Med Inc., Warwick, RI) and maintained below $10 \mathrm{k} \Omega$. The G2 electrode was placed directly above the motor point of the BB muscle. The Gl electrode was placed on the biceps tendon. Both $\mathrm{Gl}$ and G2 were standard size (20 mm diameter) $\mathrm{Ag} / \mathrm{AgCl}$ electrodes (Grass FE9- 40-5, Astro-Med Inc., Warwick, RI). On the upper portion of the biceps muscle a self-adhesive ground electrode was placed, between G2 and the point of stimulation on the musculocutaneous nerve. The EMG system (Grass, P511, Astro-Med Inc., W Warwick, RI) amplified the evoked potentials (1000×) before they were band-passed filtered $(3-1000 \mathrm{~Hz})$. the biceps brachii $\mathrm{H}$-wave that was recorded by EMG and then stimulation with higher intensities to activate axons of alphamotor neurons and M-response was recorded before placing the electrodes [27].

III- MRI:- MRI-images were obtained under 2 consecutive conditions [28]: 1] at rest (T2- rest) after 30min of supine lying, 2] immediately following exercise to avoid regain the resting metabolic condition of the muscles. According to Cagnie, et al. [18], a rest period of $45 \mathrm{~min}$ is required, which allows_ $98 \%$ of the T2 shifts to be recovered. There were five transaxial slices before and after the intervention, $5-\mathrm{mm}$ thick with $10-\mathrm{mm}$ space between each slice, including one at 
the proximal half of the muscle (biceps brachii) and two slices above and two slices below this point. For T2 calculation, a multi-spin-echo sequence was used: repetition time of 2,500 ms; echo times 10-161.6 ms with steps of $10.1 \mathrm{~ms}$ (16echos), field of view $256 \mathrm{~mm}$, matrix 128 $\mathrm{x} 128$, and voxel size $2 \times 2 \times 5 \mathrm{~mm}$. Total acquisition time was $5 \mathrm{~min}$, $12 \mathrm{~s}$. Imaging procedures were identical for the resting scan and the scan after exercise. T2 increase values, which are known as the change between $\mathrm{T} 2$ values at rest and after exercise.

b) Training procedures: I- Group (A): received autogenetic inhibition technique in form of maximum isometric muscle contraction (MIC) hold for 6 seconds and then relax for 6 seconds for the agonist muscle (biceps brachii) repeated 5 times using isokinetic dynamometer from setting position with the elbow angle constant at $120^{\circ}$ during the isometric contraction [29,] Rok et al 2008). H\M ratio was done to biceps brachii muscle before, directly after intervention and after $2 \mathrm{~min}$ post intervention. MRI done before the intervention at rest and directly after intervention.

II-Group (B): received reciprocal inhibition technique in form of maximum isometric muscle contraction (MIC) hold for 6 seconds and then relax for 6 seconds for the antagonist muscles (Triceps brachii) repeated 5 times using isokinetic dynamometer from setting position with the elbow angle constant at $120^{\circ}$ during the isometric contraction [29,30]. $\mathrm{H} \backslash \mathrm{M}$ ratio was done to biceps brachii muscle before, directly after intervention and after 2 min postintervention. MRI done before the intervention at rest and directly after intervention to the biceps brachii muscle.

c) Data management: After scanning, the images were transferred to a computer for calculation of muscle T2 value using ImageJ, a Java-based version of the public domain NIH Image software. USA (Research Services Branch, National Institutes of Health). Regions of interest (ROI) were identified on the T2 images: on the base of its clearest visualization on the bulkiest area of the muscle. When defining a ROI, non-muscular tissue within the ROI, such as fat, fascia, and vessels, was avoided.

\section{Statistical analysis}

Descriptive statistics (mean and standard deviation) were computed for all data. Friedman test was conducted to compare the mean differences in the outcome measures scores within both groups at three occasions (before intervention, immediately after intervention, and after 2 minutes of intervention). The post hoc test was used for pairwise comparison. The Mann-Whitney $U$ test was conducted to compare the mean differences between groups. The level of significance for all statistical tests was set at P less than 0.05. All statistical analyses were performed with the Statistical Package for Social Sciences version 20 for windows.

\section{Results \\ Pilot study}

Before the beginning of the study, pilot study was performed on 7 RT. Hemiplegic children and 5 Normal children (as a control group). Statistical analysis of the pilot study revealed that there was no need for control group as there is no intervention and no significance difference for the control group. Power analysis was initially done for the pilot study to calculate the sample size. These assumptions created a sample size of fifteen children for each group.

\section{Demographic characteristics}

There was no significant difference between the two groups in age weight and height $(\mathrm{P}>0.05)$ as illustrated in table 1 . There was no significant difference between groups in gender distribution, spasticity, affected side and MACS as Chi-squared value was $0.65,0.52$ and 0.42 respectively $(\mathrm{P}>0.05)$.

\section{Pretreatment comparison between the two groups}

There was no significant difference between the two groups in all measured variables before intervention $(\mathrm{P}>0.05)$ as illustrated in table 2 .

\section{Pre-post treatment comparison for each group}

As illustrated in table 3 there was significance difference for both groups in $\mathrm{H} \backslash \mathrm{M}$ ratio when comparing pre and post immediate intervention and immediately and after $2 \mathrm{~m}$ of interventions $(\mathrm{P}<0.05)$ with no significance difference during comparing Before and after 2 $\mathrm{m}$ of intervention $(\mathrm{P}>0.05)$. There was significant difference in pre and immediate post intervention comparison in $\mathrm{T} 2$ values for biceps brachii musclein-group $(\mathrm{A})(\mathrm{P}<0.05)$, with no significant difference for group $(\mathrm{B})(\mathrm{P}>0.05)$ as illustrated in table 4 .

\section{Comparison between the two groups immediately after intervention and 2 minutes post interventions}

There was a significant difference in favor of group A immediately after intervention in $\mathrm{H} \backslash \mathrm{M}$ ratio and $\mathrm{T} 2$ values for biceps brachii muscle. $(\mathrm{P}<0.05)$ and there was no significant difference between the two groups after 2 minutes of interventions in $\mathrm{H} \backslash \mathrm{M}$ ratio $(\mathrm{P}>0.05)$ as illustrated in table 5 .

Table 1. Physical characteristics of the subjects at the beginning of the study

\begin{tabular}{|c|c|c|c|}
\hline Characteristics & $\begin{array}{c}\text { Group (A) } \\
\overline{\mathrm{X}} \pm \mathrm{SD}\end{array}$ & $\begin{array}{c}\text { Group (B) } \\
\overline{\mathrm{X}} \pm \mathrm{SD}\end{array}$ \\
\hline Age (year) & $8.3 \pm 0.83$ & $8.6 \pm 0.57$ & \\
\hline Weight & $27.8 \pm 5.4$ & $28.4 \pm 3.5$ & $0.61 * *$ \\
\hline height & $120.7 \pm 6.2$ & $121.6 \pm 4.8$ \\
\hline
\end{tabular}

$\overline{\mathrm{X}}$ : Mean; SD: Standard deviation; p-value: Level of significance; **: Non-significant

Table 2. Pretreatment comparison between the groups

\begin{tabular}{|l|l|l|l|}
\hline Variables & $\begin{array}{l}\text { Group(A) } \\
\bar{X} \pm \text { SD }\end{array}$ & $\begin{array}{l}\text { Group (B) } \\
\bar{X} \pm \text { SD }\end{array}$ & P-value \\
\hline T2 values for biceps brachii muscle (ms). & $41.07 \pm 3.17$ & $40.89 \pm 3.43$ & $0.45^{* *}$ \\
\hline H $\backslash$ M ratio & $0.77 \pm 0.05$ & $0.73 \pm 0.08$ & $0.39^{* *}$ \\
\hline
\end{tabular}

$\overline{\mathrm{X}}$ : Mean SD: standard deviation p-value: level of significance $* *$ : non-significant 
Table 3. Pairwise comparison for both groups in $\mathrm{H} \backslash \mathrm{M}$ ratio immediately after intervention and after $2 \mathrm{~m}$. of intervention

\begin{tabular}{|l|l|l|l|l|l|l|}
\hline \multirow{2}{*}{ Variables } & \multicolumn{2}{l|}{ Group (A) } & \multicolumn{2}{l|}{ Group (B) } \\
\cline { 2 - 4 } & $\begin{array}{l}\text { Before and immediately } \\
\text { after intervention }\end{array}$ & $\begin{array}{l}\text { Before and after } 2 \mathrm{~m} \text { of } \\
\text { intervention }\end{array}$ & $\begin{array}{l}\text { Immediately after } \\
\text { interventions and after } \\
2 \mathrm{~m} .\end{array}$ & $\begin{array}{l}\text { Before and immediately } \\
\text { after intervention }\end{array}$ & $\begin{array}{l}\text { Before and after } 2 \mathrm{~m} \text { of } \\
\text { intervention }\end{array}$ & $\begin{array}{l}\text { Immediately after } \\
\text { interventions and after } \\
2 \mathrm{~m} .\end{array}$ \\
\hline $\mathrm{H} \backslash \mathrm{M}$ ratio & $0.001 *$ & $0.001^{* *}$ & $0.001^{*}$ & $0.21^{* *}$ \\
\hline
\end{tabular}

*: significant; $* *$ : non-significant

Table 4. Pre-and immediate after intervention comparison for both groups in $\mathrm{T} 2$ values for biceps brachii muscle

\begin{tabular}{|l|c|c|}
\hline Variables & Group (A) & Group (B) \\
\hline T2 values for biceps brachii muscle $(\mathrm{ms})$. & $0.001^{*}$ & $0.38^{* *}$ \\
\hline$*$ : significant; $* *$ : non-significant. & & \\
\hline
\end{tabular}

Table 5. Post treatment comparison between the two groups immediately after interventions and 2 minutes post interventions

\begin{tabular}{|l|c|c|}
\hline Variables & $\begin{array}{c}\text { Group(A) } \\
\bar{X} \pm \text { SD }\end{array}$ & $\begin{array}{c}\text { Group (B) } \\
\bar{X} \pm \text { SD }\end{array}$ \\
\hline T2 values for biceps brachii muscle (ms). & $48.14 \pm 2.96$ & $42.20 \pm 2.22$ \\
\hline$H \backslash M$ ratio (immediately) & $0.51 \pm 0.06$ & $0.59 \pm 0.05$ \\
\hline$H \backslash M$ ratio (2 min post) & $0.69 \pm 0.05$ & $0.72 \pm 0.08$ \\
\hline
\end{tabular}

$\overline{\mathrm{X}}$ : Mean; SD: standard deviation; P-value: level of significance; *: significant; **: Non-significant

\section{Discussion}

The result of this study demonstrated that there was a significant difference between both groups post intervention in $\mathrm{H} \backslash \mathrm{M}$ ratio of spastic muscle in favor of autogenic inhibition technique. This comes in accordance with Herbert M. How stated that during muscular contraction, autogenic inhibition is initiated in parallel (with the motor excitation), via the interneuron's that are activated by the Golgi tendon organs (GTO). It appears that when an excessive force is applied to or exerted by a muscle at varying lengths (extensions), the GTO inhibition regulates not only the frequency of discharge but also the range of firing of the motor neurons. Inhibition of gamma and alpha motor neurons resulting in muscle relaxation [31]. Golgi tendon organs functionally known as B-receptors recording active or passive tension and are sensitive to the rate of increase of tension [32].

In addition, it comes in agreement with Stuart et al., and Goslow et al. $[33,34]$ they stated that the functional significance of GTO's in moment to moment regulatory mechanisms has become increasingly evident [33,34]. Muscular contraction does elicit autogenic postsynaptic inhibition in both extensors and flexors [35]. Furthermore, if a motoneuron is not driven by the primaries and the muscle is under some tension, an increase in membrane potential may be expected due to autogenic inhibition from the tendon organs [36].

In the present study, our choice to use autogenic inhibition was supported by Herbert who reported that the level of force applied to, or exerted by a muscle, as well as its rate of change, determine the discharge frequency of its firing motor units and that of the GTO's. In addition, the thresholds of the interneuron's in the intermediate nucleus to natural (tension and stretch/extension) and electrical stimuli suggest that their excitation is dependent on group Ib afferents, which is an essential function of GTO recruitment [31].

Concerning the results of reciprocal inhibition group, the results of our study come in accordance with Gyan and Gerald [37] whom stated that excitation of primary spindle afferent fibers from the gastrocnemius and soleus muscles may produce a period of electrical silence on both homonymous and antagonistic muscle groups. The silence of the antagonist is due to reciprocal inhibition over neural pathways within the spinal cord. The homonymous silence is also initiated by spinal mechanisms, but the extended duration of this silence is determined by mechanical factors of the contracting muscle [37].

According to the data analysis in the current study, the results of autogenic inhibition group revealed that there was a significant reduction of post-intervention muscular spasticity than reciprocal inhibition group. It comes in agreement with Karen and Caroline [38] they concluded that as the results of short-latency inhibition to both the quadriceps and hamstrings upon stimulation of their respective antagonist nerve. Group I afferents seem likely to be responsible for the early part of this inhibition suggesting that disynaptic Ia inhibition can be evoked to both the quadriceps and hamstrings. In addition, disynaptic Ia inhibition occurred more regularly and with greater amplitude in the hamstrings compared with the quadriceps, indicating that the disynaptic Ia inhibition present in the quadriceps and hamstrings is not equivalent in both directions and is consequently not actually 'reciprocal'. Reflexes can be modulated at dissimilar points in range and under various conditions such as the degree of contraction, or even the speed of the task [39-41]. Furthermore, quadriceps undergo a varying degree of reflex facilitation and inhibition as the knee moves through the gait cycle [42]. Although this finding is interesting from a clinical perspective. Clinicians may use RI as a clarification for the effect of some manual therapy handlings such as some techniques of muscle energy and PNF. In hypothesizing the mechanism of effect, clinicians should question any presumption that reciprocal inhibition is equal and opposite between any agonist-antagonist muscle pair during every task [38]. Our data are supported by Neha and Sheila [43] whom reported that reciprocal inhibition was absent and replaced by reciprocal facilitation in 10 of 15 chronic post-stroke hemiparesis individuals. Reciprocal facilitation was associated with low Fugl-Meyer scores and slow walking speeds but not with overactive Achilles tendon reflexes. Decreased RI is not a constant finding post-stroke and is more relevant related to walking ability and movement impairment than to spasticity. Phenomena other than decreased RI may contribute to post-stroke spasticity. Furthermore our results reinforced by Moore and Kukulka [44] whom concluded that after voluntary contraction H-reflex amplitudes were strongly depressed (mean maximum decrease $=83.3 \%$ ) indicating a reduction in alpha $\mathrm{MN}$ reflex excitability, indicate that proprioceptive neuromuscular facilitation techniques (eg, holdrelax) purported to produce a phase of relaxation following voluntary 
contraction do appear to produce a strong, but brig neuromuscular inhibition that may be clinically useful for applying stretch.

The results of this study show that muscle functional MRI was used to illustrate the specific activation levels and recruitment patterns of the muscles after contraction. According to the data analysis in the current study, the results of autogenic inhibition group revealed that there was a significant increasing of post-intervention in transverse relaxation time (T2) than reciprocal inhibition group it come in agreement with [45] whom concluded that muscle functional MRI can be used to characterize the specific activation levels and recruitment patterns of the superficial and deep cervical flexors during different cervical flexion exercises. In addition, it come in agreement with Danneels et al. [46]. Whom demonstrated that Quantitative T2-images (muscle functional MRI) used to evaluate low back pain on lumbar muscle activities which concluded that $\mathrm{T} 2$-values were significantly higher in the exercise condition (without pain) compared to the resting condition and T2shift was significantly lower in the exercise-with-pain compared to the exercise-without pain condition for all muscles.

The result of this study demonstrated that there was a significant difference between both groups post intervention in T2-value MRI images in spastic muscle in favor of autogenic inhibition group that result in increased the T2-values than reciprocal inhibition group, it was supported by Shellock et al [47], who reported that Five subjects performed exhaustive exercise by doing isolated concentric actions (raising a dumbbell, flexing at the elbow) and eccentric muscle actions (lowering a dumbbell, extending the contra lateral arm). T2-weighted MR images of the arms were obtained immediately before and after exercise. Muscles that achieved concentric actions had increases in signal intensity, whereas muscles that achieved eccentric actions showed little or no change. T2 relaxation times increased significantly ( $p$ less than 0.01 ) in all volunteers, but T2 relaxation times for the muscles that achieved concentric actions were significantly higher than those for muscles that achieved eccentric actions. Furthermore, our results supported by Ronald A. and Barry [48] whom reported that muscle functional MRI is well-suited for examining normal and abnormal patterns of muscle recruitment within individuals during exercise and may prove useful for diagnosing and monitoring the progression of motor neuron disease.

\section{Clinical Implications}

The findings of our study have revealed that autogenic inhibition has more influence on decreasing spasticity than reciprocal inhibition. According to our findings autogenic inhibition has double significance on the results of $\mathrm{H} \backslash \mathrm{M}$ ratio and mfMRI immediately as it done on the same tested muscle (biceps brachii) otherwise reciprocal inhibition has an immediate effect on the $\mathrm{H} \backslash \mathrm{M}$ ratio results only as it done at the antagonist muscle (Triceps brachii). These results are compatible with current practice techniques such as the hold-relax technique. The patient is usually taken to the end of the passive range of motion and resistance applied to a voluntary "hold" contraction, followed by an increase in the manual stretch. Therapists may also have considered that faster relaxation of the contraction appears likely to produce greater inhibition [49]. The results of our study, therefore, may be generalized beyond our experimental protocol [50-53].

\section{Limitations}

Age of sample size was limited.

\section{Conclusions}

Autogenic inhibition is more effective than reciprocal inhibition techniques on decreasing hemiplegic children spasticity.

\section{Acknowledgement}

We are so grateful to our colleagues in the physical therapy department, for their encouraging discussions and valuable help and support to complete this work. Words can't express my deep thanks to all subjects participated in this study.

\section{References}

1. Sharman M, Cresswell A, Riek S (2006) Proprioceptive Neuromuscular Facilitation Stretching. Sports Medicine 36: 929-939.

2. Chaitow L, Crenshaw K (2006) Muscle energy techniques. Elsevier Health Sciences

3. Tanaka R (1974) Reciprocal Ia inhibition during voluntary movements in man. Exp Brain Res 21: 529-540. [Crossref]

4. Crone C, Hultborn H, Jespersen B, Nielsen J (1987) Reciprocal Ia inhibition between ankle flexors and extensors in man. J Physiol 389: 163-185. [Crossref]

5. Crone C, Nielsen J (1994) Central control of disynaptic reciprocal inhibition in humans Acta Physiol Scand 152: 351-363.

6. Morita H, Crone C, Christenhuis D, Petersen NT, Nielsen JB (2001) Modulation of presynaptic inhibition and disynaptic reciprocal Ia inhibition during voluntary movement in spasticity. Brain 124: 826-837. [Crossref]

7. Okuma Y, Lee RG (2002) Reciprocal inhibition in hemiplegia: correlation with clinical features and recovery. Can J Neurol Sci 23: 15-23. [Crossref]

8. Jankowska E (1992) Interneuronal relay in spinal pathways from proprioceptors. Prog Neurobiol 38: 335-378. [Crossref]

9. Pierrot-Deseilligny E, Morin C, Bergego C, Tankov N (1981) Pattern of group I fibre projections from ankle flexor and extensor muscles in man. Exp Brain Res 42: 337-350. [Crossref]

10. Pierrot-Deseilligny E, Bergego C, Katz R (1982) Reversal in cutaneous of Ib pathways during human voluntary contraction. Brain Res 233: 400-403. [Crossref]

11. Gossard JP, Brownstone RM, Barajon I, Hultborn H (1994) Transmission in a locomotor-related group Ib pathway from hindlimb extensor muscles in the cat. Exp Brain Res 98: 213-228. [Crossref]

12. Delwaide PJ, Oliver E (1988) Short-latency autogenic inhibition (IB inhibition) in human spasticity. J Neurol Neurosurg Psychiatry 51: 1546-1550.

13. Delwaide PJ, Pennisi G (1994) Tizanidine and electrophysiologic analysis of spinal control mechanisms in humans with spasticity. Neurology 44: 21-27.

14. Downes L, Ashby P, Bugaresti J (1995) Reflex effects from Golgi tendon organ (Ib) afferents are unchanged after spinal cord lesions in humans. Neurology 45: 1720-1724.

15. Watson L, Stanley F (1999) Report of the Western Austrlian Cerebral Palsy Register To birth year 1994. Perth, TVW Telethon Institute for Child Health Research.

16. Haan E, Chan A (2004) The South Australian Cerebral Palsy Register - Annual Report 2003. Adelaide, The South Australian Birth Defects Register.

17. Boyd RN, Morris ME, Graham HK (2001) Management of upper limb dysfunction in children with cerebral palsy: a systematic review. Eur J Neurol 8 Suppl 5: 150-166. [Crossref]

18. Cagnie B, Elliott JM, O'Leary S, D'hooge R, Dickx N, et al. (2011) Muscle functional MRI as an imaging tool to evaluate muscle activity. J Orthop Sports Phys Ther 41: 896-903. [Crossref]

19. Meyer RA, Prior BM (2000) Functional magnetic resonance imaging of muscle. Exerc Sport Sci Rev 28: 89-92. [Crossref]

20. Mayer JM, Graves JE, Clark BC, Formikell M, Ploutz-Snyder LL (2005) The use of magnetic resonance imaging to evaluate lumbar muscle activity during trunk extension exercise at varying intensities. Spine $30: 2556-2563$.

21. Adams GR, Duvoisin MR, Dudley GA (1992) Magnetic resonance imaging and electromyography as indexes of muscle function. J Appl Physiol (1985) 73: 1578-1583. [Crossref]

22. Fisher MJ, Meyer RA, Adams GR, Foley JM, Potchen EJ (1990) Direct relationship between proton T2 and exercise intensity in skeletal muscle MR images. Invest Radiol 25: 480-485.

23. Fleckenstein JL, Canby RC, Parkey RW, Peshock RM (1988) Acute effects of exercise on MR imaging of skeletal muscle in normal volunteers. AJR Am J Roentgenol 151: 231-237. [Crossref] 
24. Patten C, Meyer RA, Fleckenstein JL (2003) T2 mapping of muscle. Semin Musculoskelet Radiol 7: 297-305. [Crossref]

25. Schonfeld-Warden N, Warden CH (1997) Pediatric obesity. An overview of etiology and treatment. Pediatr Clin North Am 44: 339-361. [Crossref]

26. Pierrot-Deseilligny E, Mazevet D (2000) The monosynaptic reflex: a tool to investigate motor control in humans: interest and limit. Clin Neurophysiol 30: 67-80. [Crossref]

27. Kristina M Calder, Lesley-Ann Hall, Steve M Lester, J Greig Inglis and David A Gabriel (2005) Reliability of the biceps brachii M-wave. J Neuroengineering Rehabil 2: 33.

28. Dickx N, Cagnie B, Achten E, Vandemaele P, Parlevliet T, et al. (2008) Changes in lumbar muscle activity because of induced muscle pain evaluated by muscle functional magnetic resonance imaging. Spine 33: E983-E989.

29. Boettcher CE, Ginn KA, Cathers I (2008) Standard maximum isometric voluntary contraction tests for normalizing shoulder muscle EMG. J Orthop Res 26: 1591-1597. [Crossref]

30. Istenic R, Holobar A, Gazzoni M, Zazula D (2008) Motor Control Information Extracted from Surface EMG as Muscle Force Estimation. WSEAS TRANSACTIONS on BIOLOGY and BIOMEDICINE.

31. Miller H (1982) The role of autogenic inhibition in the reduction of muscle splinting. J Can Chiropr Assoc.

32. Matthews BH (1933) Nerve endings in mammalian muscle. $J$ Physiol 78: 1-53. [Crossref]

33. Stuart DG, Mosher CG, Gerlach RL (1972) Properties of central connections of Golgi tendon organs with special reference to locomotion. In: Banker BQ (eds.) Research in muscle development and the muscle spindle. Amsterdam: Excerpta Medica 437-462.

34. Goslow GE, Stuart Ek, Nemeth WC, Stuart DG (1973) The cat step cycle: responses of muscle spindles and tendon organs to passive stretch within the locomotive range. Brain Res 60: 35-54.

35. Coombs JS, Eccles JC, Fatt P (1955) The specific ionic conductance and the ionic movements across the motoneuronal membrane that produces the inhibitory postsynaptic potential. J Physiol 130: 326-373. [Cossref]

36. Granit R, Kellerth J, Szumski AJ (1966) Intracellular autogenetic effects of muscular contraction on extensor motoneurons. The silent period. J Physiol 182: 484-503. [Crossref]

37. Agarwal GC, Gottlieb GL (1972) The muscle silent period and reciprocal inhibition in man. J Neurol Neurosurg Psychiatry 35: 72-76. [Crossref]

38. Hamm K, Alexander CM (2010) Challenging presumptions: is reciprocal inhibition truly reciprocal? A study of reciprocal inhibition between knee extensors and flexors in humans. Man Ther 15: 388-393. [Crossref]
39. Lavoie BA, Devanne H, Capaday C (1997) Differential control of reciprocal inhibition during walking versus postural and voluntary motor tasks in humans. J Neurophysiol 78: $429 \mathrm{e} 38$.

40. Leonard CT, Sandholdt DY, Mcmillan JA (1999) Long-latency contribution to reciprocal inhibition during various levels of muscle contraction. Brain Research 817 (1e2): 1e12.

41. Kido A, Tanaka N, Stein RB (2004) Spinal reciprocal inhibition in human locomotion. Journal of Applied Physiology 2004; 96:1969e77. [Crossref]

42. Larsen B, Voigt M (2006) Quadriceps H-reflex modulation during pedaling. $J$ Neurophysiol 96: 197-208. [Crossref]

43. Bhagchandani N, Ivens SS (2012) Reciprocal inhibition post-stroke is related to reflex excitability and movement ability. Clin Neurophysiol 123: 2239-2246 [Crossref]

44. Moore MA and Kukulka CG (1991) Depression of Hoffman reflexes following voluntary contraction and implications for proprioceptive neuromuscular facilitation therapy. Phys Ther 71: 321-333. [Crossref]

45. Cagnie B, Dickx N, Peeters I, Tuytens J, Achten E, et al. (2007) The use of functional MRI to evaluate cervical flexor activity during different cervical flexion exercises $J$ Appl Physiol 104: 230-235.

46. Lieven D, Barbara C, Roseline D, Yves D, Geert C, Guy V, et al. (2015) The effect of experimental low back pain on lumbar muscle activity in people with a history of clinical low back pain - a muscle functional MRI study. J Neurophysiol.

47. Shellock FG, Fukunaga T, Mink JH, Edgerton VR (1991) Acute effects of exercise on MR imaging of skeletal muscle: concentric vs eccentric actions. Am J Roentgenol 156 : 765-768. [Crossref]

48. Meyer RA, Prior BM (2000) Functional Magnetic Resonance Imaging of Muscle Exercise and Sport Sciences Reviews. 28: 89-92. [Crossref]

49. Schieppati M, Crenna P (1984) From activity to rest: gating of excitatory autogenetic afferences from the relaxing muscle in man. Exp Brain Res 56: 448-457. [Crossref]

50. Crone C, Hultborn H, Jespersen B, Nielsen J (1987) Reciprocal Ia inhibition between ankle flexors and extensors in man. J Physiol 389: 163-185. [Crossref]

51. Crone C, Nielsen J, Petersen N, Ballegaard M, Hultborn H (1994) Disynaptic reciprocal inhibition of ankle extensors in spastic patients. Brain 117: 1161-1168.

52. Fleckenstein JL, Canby RC, Parkey RW, Peshock RM (1988) Acute effects of exercise on MR imaging of skeletal muscle in normal volunteers. AJR Am J Roentgenol 151: 231-237. [Crossref]

53. Okuma Y, Mizuno Y, Lee RG (2002) Reciprocal Ia inhibition in patients with asymmetric spinal spasticity. Clin Neurophysiol 113: 292-297. [Crossref]

Copyright: $\odot 2018$ Serag ME. This is an open-access article distributed under the terms of the Creative Commons Attribution License, which permits unrestricted use, distribution, and reproduction in any medium, provided the original author and source are credited. 